\title{
Review of 2007
}

\section{Clinical pharmacology - providing tools and expertise for translational medicine}

\author{
J. K. Aronson, A. Cohen, L. D. Lewis \\ British Journal of Clinical Pharmacology
}

'There is an urgent need to develop individuals who have the ability to combine a firm grounding in the principles of basic and clinical pharmacology with the most modern research technologies to address complex (patho)physiological questions'

The Wellcome Trust, 2007

Those who remember their school Latin will recall the paradigm for regular verbs such as 'to love': amo, amare, amavi, amatum - I love (present tense), to love (present infinitive), I have loved (perfect tense), loved (past participle). But the paradigm for the verb 'to carry' is irregular: ferro, ferre, tuli, latum. It comes, in fact, from three different roots. And that explains the connection between words such as refer and relate, confer and collate, transfer and translate [1].

To transfer means to carry over or bring over, and by extension to change over. To translate carries a similar meaning, to change or adapt to another use. This meaning, which dates from the late 14th century, includes such implications as physical or metaphorical transference and the interchangeability of languages, and it extends the meaning of transfer. 'Bottom, thou art translated,' says Snug in A Midsummer Night's Dream; not only has Bottom been changed physically into an ass; his metaphorically asinine nature has also been translated.

These two ideas of carrying over and changing or adapting merge in the term 'translational medicine', which was first formulated in the mid 1990s and caught on quickly enough for a journal, The Journal of Translational Medicine, to be founded in 2003 [2]. Other non-identical but overlapping terms, such as 'systems biology' and 'experimental medicine' or'experimental therapeutics', have also emerged in an attempt to cover the spectrum of what is increasingly being alliteratively referred to as science 'from bench to bedside' and 'from molecules to man'.

However, like so many apparently new ideas, this one is as old as the hills - only the terms are new. Clinical aca- demics have been interested in the two-way street that links basic science and clinical applications ever since clinical research was invented. And clinical pharmacology is the subject that best exemplifies this idea: its activities encompass everything from the molecular end of drug therapy to the use of medicines in individuals and populations (Figure 1) [3].

In this short review we cannot cover all the aspects of the tools of clinical pharmacology that make it relevant to translational medicine; we shall simply highlight a few examples.

\section{Pharmacogenomics}

The publication of the sequence and initial analysis of the human genome in 2001 [4] fuelled media hype and high expectations concerning 'personalized medicine'. In the early $21^{\text {st }}$ century this idea has become closely linked to pharmacogenetics and pharmaco-genomics [5], although clinical pharmacologists, using non-genetic as well as genetic tools, have always espoused the concept of individualized drug therapy, even though it is a holy grail that cannot always be obtained (for example, in mass strategies such as immunization). Moreover, individual variability in drug response depends on non-genetic and environmental factors, in addition to genotype [6]. But pharmacogenomics is potentially a major method in the development of translational medicine and is a current buzz-word in biomedical research and research funding, as demonstrated by the MRC-NIHR Efficacy and Mechanism Evaluation (EME) Programme in the UK, due to be launched later this year [7], and the NIH Clinical and Translational Science Awards in the USA [8]. Pharmacogenomic tools for translational medicine were well represented in the Journal during 2007.

Dickinson et al. [9] used a mechanistic populationbased pharmacokinetic (PK) and pharmacodynamic (PD) 
providing tools and expertise for translational medicine $\mathrm{B}] \mathrm{CP}$

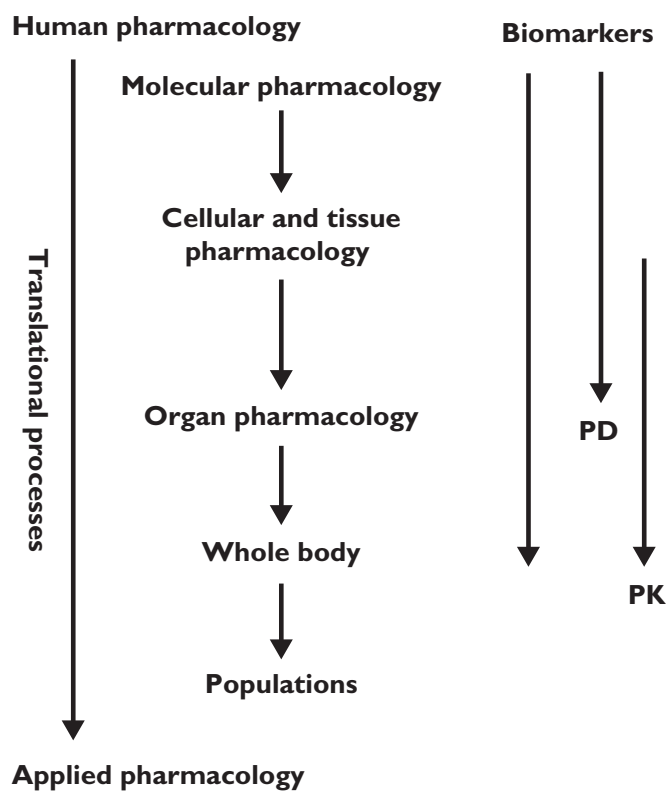

\begin{tabular}{l|l}
\multicolumn{2}{|c}{ “Bench" } \\
Receptor pharmacology \\
Enzyme pharmacology \\
Autacoid pharmacology \\
Cellular pharmacology \\
Transport pharmacology \\
Kinetic/dynamic studies \\
Pharmacogenetics \\
Drug metabolism \\
Kinetic/dynamic studies \\
Adverse drug reactions/ \\
interactions \\
Practical therapeutics \\
Monitoring drug therapy \\
Clinical toxicology \\
Clinical trials \\
Pharmacoepidemiology \\
\end{tabular}

\section{Figure 1}

Clinical pharmacological tools for translational medicine (adapted from [3])

model to define the size and power of in vivo studies needed to discern the effect of genotype on PK and PD, using variants of the CYP2C9 genotype $\left({ }^{*} 2 /{ }^{*} 2, * 2 / * 3\right.$, and ${ }^{*} 3 /{ }^{*} 3$ ) and (S)-warfarin as a model. Their modelling suggested that about 250 subjects were needed to detect a difference in anticoagulant response between genotypes. Experimental PK and PD comparisons between wild-type and other individual CYP2C9 genotypes showed that only $21 \%$ of cases (20 of 95 comparisons within 11 PD and four PK-PD studies) reported statistically significant differences. Simulations of studies enriched with specific genotypes showed that only three and five subjects were required to detect differences in PK and PD between the wild type and the $* 3 / * 3$ genotype. An extension of these sophisticated studies would add information about genetic variants of vitamin $\mathrm{K}$ epoxide reductase complex 1 (VKORC1 - the pharmacological target of warfarin action), and such analyses could be used to design and power more efficient clinical studies of the problem of variability in anticoagulant responses.

The UGT1A $1 * 28$ polymorphism of UDPglucuronyltransferase reduces UGT1A1 enzyme activity, via an extra TA repeat in the promoter region. During 2006 the FDA modified the drug labelling of the cytotoxic drug irinotecan (CPT-11) and suggested that genotyping for this polymorphism could assist in guiding irinotecan dosing, thus avoiding serious neutropenia [10]. Peterkin et al. measured UGT1A1 enzyme activity with probe substrates and protein expression levels ex vivo in human hepatic microsomes [11]. Their results suggested that the
UGT1A $1 * 28$ polymorphism contributes about $40 \%$ of the variability in UGT1A1 enzyme activity. This is in keeping with clinical data that suggest that UGT1A $1 * 28$ is more important when using high-dose irinotecan [12].This study and that of Dickinson et al. suggest that to define better the extent to which genotype contributes to individual variability in drug responses we must study the genetic variability in the proteins that are involved in the drug pathways (targets, drug transporters, metabolizing enzymes). Such genetic information is being compiled, and several drug pathways have been described in the PharmGKB pharmacogenetics and pharmacogenomics knowledge database [13]. The use of such information should lead to meticulously planned clinical studies to test how this genetic knowledge can guide optimization of drug therapy.

In our sister journal, The British Journal of Pharmacology, Rognan introduced and comprehensively reviewed chemogenomics [14]. This discipline systematically investigates the biological effect of a spectrum of small ligands on a wide array of macromolecular targets. Because the quantity of existing data (compounds, targets, and assays) and of the resulting information (gene/protein expression levels and binding constants) is too large for manual manipulation, information technology plays a crucial role in planning, analysing, and predicting chemogenomic data. These methods permit navigation of either ligand or target space and should lead to more scientifically driven drug discovery paradigms.

In order to translate further advances in the fields of pharmacogenomics (as 'personalized medicine') or 
chemogenomics (in the clinical development of novel therapeutics), a multi-disciplinary team, with clinical pharmacologists in the forefront as experts in translational techniques, is a prerequisite.

\section{Biomarkers}

Biomarkers are essential tools in translational medicine [15] (Figure 1), and examples appear in the Journal from time to time [16]. During 2007, studies of different types of new potential biomarkers included plasma deoxynucleoside concentrations in cancer chemotherapy with capecitabine [17], the flurbiprofen urinary metabolite ratio as an in vivo measure of CYP2C9 activity [18], and metabolite profiles as biomarkers for the pharmacological effects of thiazolidinediones in diabetes mellitus [19]. Other studies involved the use of biomarkers that are already well known, such as arterial stiffness in hypertension [20], prolactin secretion as a measure of dopaminergic function [21], and cortisol and ACTH as markers of the effects of exogenous glucocorticoids [22]. Not all of the new potential biomarkers will prove useful in predicting outcomes, but even if they do not, such studies add to our cumulative understanding of the pharmacology of the relevant drugs.

\section{New methods}

In 2007 the Journal published several papers dealing with other types of new techniques. For example, Ndovi et al. described an intriguing method for measuring drug concentrations in the male genital tract using a device for collecting split fractions of the ejaculate in healthy men [23]; van der Schueren et al. described a technique for studying capsaicin-induced neurogenic inflammation [24]; and Drummond studied the effect of electrical stimulation on the axon reflex [25]. These methods are all of potential use in translational medicine. Indeed, the Editors of the Journal have recognized the importance of such studies by awarding the 2007 BJCP Prize to Dr Ndovi", jointly with two other trainees in clinical pharmacology. These papers demonstrate the power of clinical pharmacological methods as translational tools.

\section{Clinical pharmacology: providing tools and expertise for translational medicine}

The British Journal of Clinical Pharmacology is not The British Journal of Translational Medicine, because clinical pharmacology is more than translational medicine. But much of

*We are sorry to report that Dr Ndovi died during 2007; this award is posthumous. translational medicine will be served by clinical pharmacologists and the tools that they provide. This is reflected in many of the articles that appear in the Journal, only a few of which we have highlighted here.

The recent initiative of the Wellcome Trust in establishing interdisciplinary training programmes for clinicians in translational medicine and therapeutics [26] emphasizes that as translational medicine develops it will continue to depend heavily on the methods of clinical pharmacology and the expertise of its practitioners. The opening paragraph of the Trust's call for applications says it all:'There is an urgent need to develop individuals who have the ability to combine a firm grounding in the principles of basic and clinical pharmacology with the most modern research technologies to address complex (patho)physiological questions. Such individuals will play a key role in shaping the interdisciplinary research that underpins translational medicine and therapeutics.' We concur and could not have put it better.

\section{REFERENCES}

1 Aronson JK. Overate? BMJ 2000; 320: 625.

2 Marincola FM. Translational medicine: a two-way road. J Transl Med 2003; 1: 1.

3 Aronson JK. On the waterfront - the breadth and depth of clinical pharmacology. Br J Clin Pharmacol 2004; 57: 693-4.

4 Lander ES, Linton LM, Birren B, Nusbaum C, Zody MC, Baldwin J, et al.; International Human Genome Sequencing Consortium. Initial sequencing and analysis of the human genome. Nature 2001; 409: 860-921.

5 O'Shaughnessy KM. HapMap, pharmacogenomics, and the goal of personalized prescribing. Br J Clin Pharmacol 2006; 61: 783-6.

6 Begg EJ. Individualizing drug therapy, and 'men behaving badly'. Br J Clin Pharmacol 2004; 58: 449-51.

7 National Institute for Health Research. The Efficacy and Mechanism Evaluation (EME) programme. http://www.nihr. ac.uk/programmes_research_programmes_eme.aspx (last accessed 4 January 2008).

8 National Center for Research Resources. Clinical and Translational Science Awards. http://www.ncrr.nih.gov/ clinical_research_resources/clinical_and_translational_ science_awards (last accessed 4 January 2008).

9 Dickinson GL, Lennard MS, Tucker GT, Rostami-Hodjegan A. The use of mechanistic DM-PK-PD modelling to assess the power of pharmacogenetic studies - CYP2C9 and warfarin as an example. Br J Clin Pharmacol 2007; 64: 14-26.

10 Yong WP, Innocenti F, Ratain MJ. The role of pharmacogenetics in cancer therapeutics. Br J Clin Pharmacol 2006; 62: 35-46.

11 Peterkin VC, Bauman JN, Goosen TC, Menning L, Man MZ, Paulauskis JD, Williams JA, Myrand SP. Limited influence of 
UGT1A $1 * 28$ and no effect of UGT2B7*2 polymorphisms on UGT1A1 or UGT2B7 activities and protein expression in human liver microsomes. Br J Clin Pharmacol 2007; 64: 458-68.

12 Hoskins JM, Goldberg RM, Qu P, Ibrahim JG, McLeod HL. UGT1A $1{ }^{*} 28$ genotype and irinotecan-induced neutropenia: dose matters. J Natl Cancer Inst 2007; 99: 1290-5.

13 PharmGKв. The pharmacogenetics and pharmacogenomics knowledge database. http://www.pharmgkb.org/search/ browse.action?browseKey=pathways (last accessed: 4 January 2008).

14 Rognan D. Chemogenomic approaches to rational drug design. Br J Pharmacol 2007; 152: 38-52.

15 Aronson JK. Biomarkers and surrogate endpoints in monitoring therapeutic interventions. In: Glasziou P, Irwig L, Aronson JK, editors. Evidence-based Medical Monitoring: From Principles to Practice. Oxford: Wiley-Blackwell, 2008.

16 Aronson JK. Biomarkers and surrogate endpoints. Br J Clin Pharmacol 2005; 59: 491-4.

17 Li KM, Rivory LP, Hoskins J, Sharma R, Clarke SJ. Altered deoxyuridine and thymidine in plasma following capecitabine treatment in colorectal cancer patients. $\mathrm{Br} \mathrm{J}$ Clin Pharmacol 2007; 63:67-74.

18 Zgheib N K, Frye RF, Tracy TS, Romkes M, Branch RA. Evaluation of flurbiprofen urinary ratios as in vivo indices for CYP2C9 activity. Br J Clin Pharmacol 2007; 63: 477-87.

19 van Doorn M, Vogels J, Tas A, Van Hoogdalem EJ, Burggraaf J, Cohen A, Van der Greef J. Evaluation of metabolite profiles as biomarkers for the pharmacological effects of thiazolidinediones in type 2 diabetes mellitus patients and healthy volunteers. Br J Clin Pharmacol 2007; 63: 562-74.

20 Wykretowicz A, Guzik P, Krauze T, Adamska K, Milewska A, Wysocki H. Add-on therapy with doxazosin in patients with hypertension influences arterial stiffness and albuterol-mediated arterial vasodilation. $\mathrm{Br} J$ Clin Pharmacol 2007; 64: 792-5.

21 Samuels ER, Hou RH, Langley RW, Szabadi E, Bradshaw CM. Comparison of pramipexole with and without domperidone co-administration on alertness, autonomic, and endocrine functions in healthy volunteers. Br J Clin Pharmacol 2007; 64: 591-602.

22 Lönnebo A, Grahnén A, Karlsson MO. An integrated model for the effect of budesonide on ACTH and cortisol in healthy volunteers. Br J Clin Pharmacol 2007; 64: 125-32.

23 Ndovi TT, Parsons T, Choi L, Caffo B, Rohde C, Hendrix CW. A new method to estimate quantitatively seminal vesicle and prostate gland contributions to ejaculate. Br J Clin Pharmacol 2007; 63: 404-20.

24 Van der Schueren BJ, de Hoon JN, Vanmolkot FH, Van Hecken A, Depre M, Kane SA, De Lepeleire I, Sinclair SR. Reproducibility of the capsaicin-induced dermal blood flow response as assessed by laser Doppler perfusion imaging. Br J Clin Pharmacol 2007; 64: 580-90.

25 Drummond PD. Repeated cycles of electrical stimulation decrease vasoconstriction and axon-reflex vasodilation to noradrenaline in the human forearm. Br J Clin Pharmacol 2007; 64: 421-7.

26 Wellcome Trust. Interdisciplinary Training Programmes for Clinicians in Translational Medicine and Therapeutics. http://www.wellcome.ac.uk/node2165.html (last accessed: 4 January 2008). 